\title{
Medical Images of Adenomyosis and Hypofertility: About Two Clinical Cases at Jean Paul Hospital 2 in Conakry, Guinea
}

\author{
Camara $\mathrm{MK}^{1 *}$, Leno William ${ }^{1}$, Mamoudou $\mathbf{M}^{1}$, Daniel $\mathrm{DG}^{2}$, Yolande $\mathrm{H}^{1}$ and Namory $\mathrm{K}^{1}$ \\ ${ }^{1}$ Department of Gynecology and Obstetrics, Donka National Hospital, Guinea \\ ${ }^{2}$ Department of Gynecology and Obstetrics of the Mother and Child Hospital, N'Djamena, Chad
}

Submission: February 22, 2018; Published: March 23, 2018

*Corresponding author: Camara Mk, Assistant Professor, Gynecology and Obstetrics Department, Donka National Hospital. BP 712, Guinea, Tel: +224620283083; Email: Camarakanta@gmail.com

\begin{abstract}
The authors report, through images of 2 clinical observations, a particular cause of hypo fertility, the implantation of pregnancy on uterine adenomyosis and the reciprocal influence with a review of the literature.
\end{abstract}

Keywords: Pregnancy; Adenomyosis; Ultrasound; Prognosis

\section{Introduction}

Adenomyosis occupies an important place in uterine pathology. It continues to raise many questions concerning its pathogenesis, but also its diagnosis and its methods of therapeutic management [1]. The thickened myometrium deviates unevenly and the uterus loses its former elasticity. A problem can occur at the beginning of pregnancy or conception in women and in the evolution of pregnancy. The discovery of a uterine adenomyoma during the confirmation of an involuntary pregnancy, motivated the pictorial description of 2 clinical cases with a review of the literature on the reciprocal influence of this association.

\section{Observation 1}

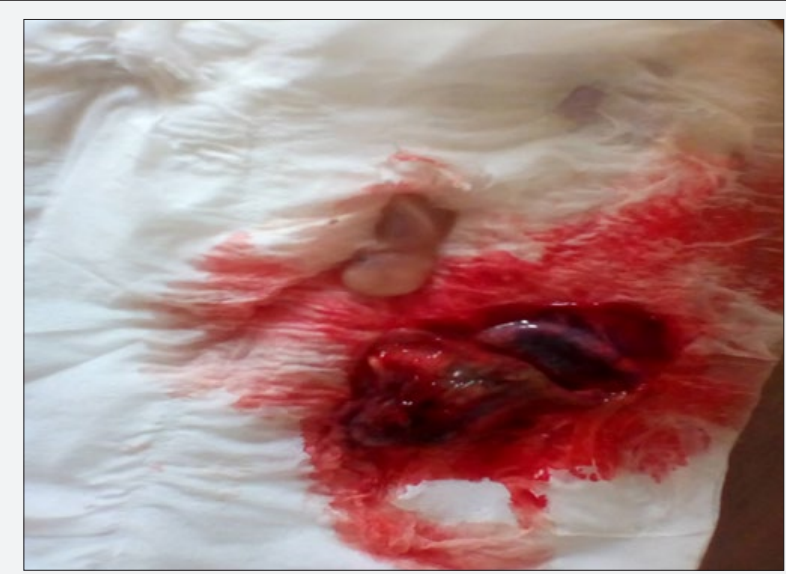

Figure 1: Adenomyosis with uterine sac and fetal death.
Mrs. CS, 30 years old, hairdresser, having in her history, 2 gestures, 1 parity with a 3-year-old living child and secondary dysmenorrhea, consults for an Ultrasonographic confirmation for the suspicion of fetal death with unspecified gestational age, date of last menstruation is unknown. The pelvic ultrasound examination performed on 13 th $/ 03 / 17$, visualized intrauterine an inactive fetus with a $37 \mathrm{~mm}$ LCC corresponding to $10 \mathrm{SA}$, a posterior placenta inserted into a posterior wall with regard to a heterogeneous mass with hypocritical foci. $50 \mathrm{~mm} x$ $25 \mathrm{~mm} \times 11 \mathrm{~mm}$ echogenic. The diagnosis of pregnancy with egg death retention estimated age $\geq 16 \mathrm{SA}$, associated with uterine adenomyosis. The management was an Intra Uterine Manual Aspiration and a progestational hormonal family planning post abortum. In Figure 1, death in utero: placenta inserted on adenomyosis.

\section{Observation 2}

Mrs DAB, 33 years old, 4th gesture, and 4 living children, accountant, consults on 18/02/2018 for metrorrhagia on an amenorrhea of 3 months without precision of the date of the last period, with a history of dysmenorrhea, the last childbirth going back to 3 years without contraception. Upon gynecological examination, the cervix is intermediate, long and open to the finger pulp at the external orifice on a soft uterus, the size of 12 weeks-amenorrhea (AW) and a good general condition. The pelvic ultrasound performed with the trans-abdominal probe of 3.5Mhz, reveals, in intrauterine, a sluggish ovular sac having within it an inactive embryo whose value of the biometry 


\section{Global Journal of Reproductive Medicine}

is lower than the age of amenorrhea; and at the level of the posterior wall of the uterus, a heterogeneous, echoic image of 41 x16 x $35 \mathrm{~mm}$ The diagnosis of unevolutive pregnancy, associated with a uterine adenomyosis is confirmed. The patient preferred ambulatory observation. She completely delivered the contain of uterus at 9am in the ward, on 20-08-2017, with an empty uterine cavity on post abortum ultrasound (Figure $2 \& 3$ ). Post-abortion contraception counseling for 6 months was done with a consent choice of combined oral contraception and obtaining consent from the couple for publication as a clinical case. In Figure 2 Uterine sac and uterine adenomyosis (from 18-02-2018) and Figure 3 Uterus with adenomyosis in immediate post abortum (from 20-02-2018)

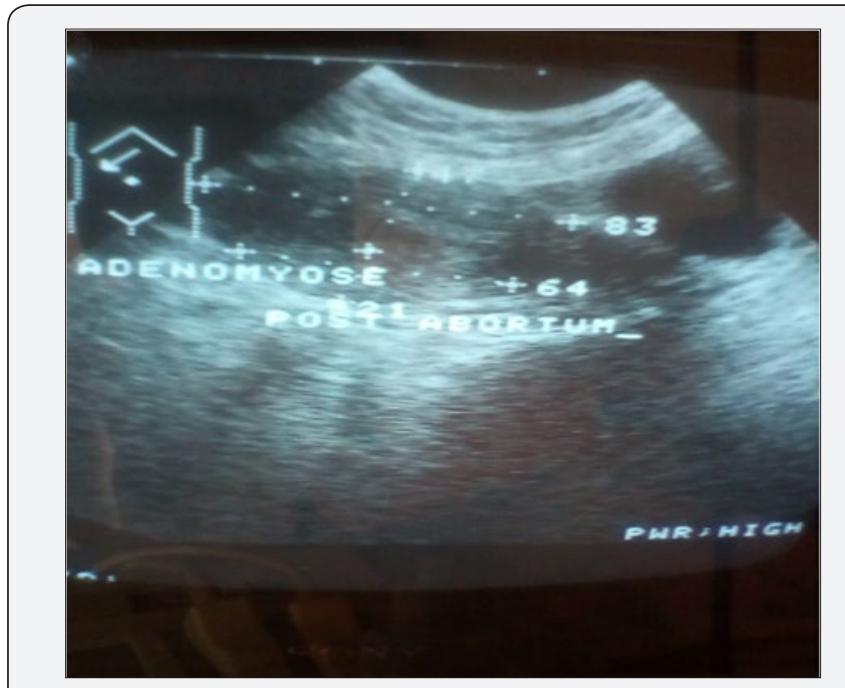

Figure 2 : 18/2/2028 uterine sac and adenomyosis.

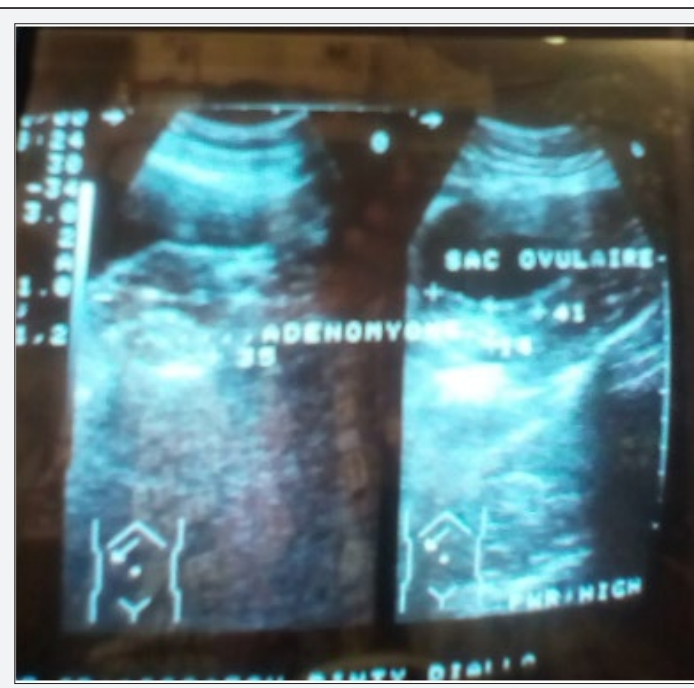

Figure 3: 20/2/2018 death fetal.

\section{Comments}

Adenomyosis was accidentally detected on pelvic ultrasound at the trans-abdominal catheter of $3.5 \mathrm{Mhz}$, during pregnancy involution (case1) or pregnancy metrorrhagia (case 2) by the diagnostic criteria retained, the presence in the uterus of an ovum sac containing or not an embryo/fetus and appendages, at the level of the myometrium, heterogeneous hyopoechoic foci with or without cystic images [2]. Numerous authors have shown the superiority of transvaginal ultrasound with sensitivity and specificity of $86 \%$ [3]. Adenomyosis occurs during a period of great activity and initially affects women over 35 years of age with multipara [4]. On the contrary, it has been observed in young women under 35 years and in multiparas in the second case. The association of adenomyosis with a normal pregnancy is possible. It seems that adenomyosis is improved by pregnancy in some cases [5]. Adenomyosis is responsible for pathophysiological disturbances that decrease the chances of pregnancy. In infertile women with adenomyosis, there is a decrease in implantation rate. Adenomyosis is responsible for a $30 \%$ decrease in the chances of pregnancy and an increase in spontaneous miscarriage rate [6]. Pregnancy can evolve to its end with the birth of a live child, if its implantation is far from adenomyomatous tissue, hence its discovery in multiparous women (case 2).

However, there is also an increase in spontaneous miscarriages, probably related to a particular myometrial activity. We attribute spontaneous abortion (case1) and in utero death (cases 1 and 2) to inadequate uterine placental blood flow related to trophoblast insertion into the posterior wall of the uterus or adenomyosis. According to Tremellen $\mathrm{K}$, has an impact rather on embryo implantation than its fertilization (OR: 0.79 (0.67-0.93)) (OR: 1.01 (0.93-1.10) [7]. For Benaglia, the asymptomatic adenomyosis did not affect implantation and pregnancy rates in FIV Routine transvaginal ultrasound will allow early detection and follow-up until the end of placentation to assess the prognosis of pregnancy [8].

\section{Conclusion}

The authors report, through images of 2 clinical observations, a particular cause of subfertility, implantation of pregnancy on uterine adenomyosis with a review of the literature.

\section{References}

1. Bousquet MC, Canis M, Bruhat MA (1999) Adenomyosis. The practitioner's review. Rev Prat 49 (3): 282-286.

2. Reinhold C, McCarthy S, Bret PM, Mehio A, Atri M, et al. (1996) Diffuse Adenomyosis: Comparison of US Endovaginal and MR Imaging with Histopathologic Correlation. Radiology 199(1): 151-158.

3. Fedele L, Bianchi S, Dorta M, Zanotti F, Brioschi D, et al. (1992) Transvaginal ultrasonography in the differential diagnosis of adenomyoma versus leiomyoma. Am J Obstet Gynecol 167(3): 603-606.

4. Fukamatsu Y, Tsukahara Y, Fukuta T(1984) A clinicopathologic study on uterine adenomyosis. Nippon Sanka Fujinka Gakkai Zasshi 36(3): 431-436.

5. Merger R, Levy J, Melchior J (2012) In: Endometriosis. Accuracy of obstetrics ( $6^{\text {th }}$ edn). Campo S, et al. (Eds.), Masson, Paris pp. 3951.

6. Vercellini P, Consonni D, Dridi D, Bracco B, Frattaruolo MP, et al. (2014) Uterine adenomyosis and in vitro fertilization outcome: a systematic review and meta-analysis. Hum Reprod 29(5): 964-772. 
7. Tremellen K, Russell P (2011) Adenomyosis is a potential cause of recurrent implantation failure during IVF treatment. Aust N Z J Obstet Gynaecol 51(3): 280-283.
8. Benaglia L, Cardellicchio L, Leonardi M, Faulisi S, Vercellini P, et al. (2014) Asymptomatic adenomyosis and embryo implantation in IVF cycles. Reprod Biomed Online 29(5): 606-611.

Your next submission with Juniper Publishers
will reach you the below assets
- Quality Editorial service
- Swift Peer Review
- Reprints availability
- E-prints Service
- Manuscript Podcast for convenient understanding
- Global attainment for your research
- Manuscript accessibility in different formats
( Pdf, E-pub, Full Text, Audio)
- Unceasing customer service
Track the below URL for one-step submission
https://juniperpublishers.com/online-submission.php


